has begun to challenge the suggestion that constrained resources have rendered African institutions powerless; rather, in the current landscape of clinical trials and global health interventions, the global south has seen yet another scramble for valued medical subjects and bodies, without which no evidence could be constructed. This makes health institutions and medical staff in "weak" states key to scientific progress and publication. African health researchers and government hospitals have leveraged this relationship by positioning themselves as interventionready to well-funded research institutions in the North, in order to fill gaps in services. While earlier scholarship in critical medical anthropology has bemoaned how Northern entities have been able to exploit existing power differentials, this paper follows Okwar and Geissler (2015) in illuminating the agency and entrepreneurialism of the health workers on the ground staffing these transnational "collaborations". Ethnographic data (semi-structured interviews and participant observation) from research on the implementation of a group antenatal care program among nurse-midwives and collaborators in East Africa is presented. Government-employed nurses in this project advocated for previously unconsidered compensation and accepted payment (in various currencies) for work done largely by others. Vignettes of agency from this research illuminate subtle challenges to the assertion of power in this context and invite discussion of unintended consequences which nonetheless reinforce and reproduce the existing system.

\section{OP ENTREPRENEURIALISM, ADAPTATION, AND DISCRETION AMONG NURSES IN A TRANSNATIONAL COLLABORATION IN MALAWI AND TANZANIA}

M McGown. Center for Community Health, Northwestern University, Chicago, USA; Department of Anthropology, University of Illinois, Chicago, USA

10.1136/bmjopen-2017-016492.5

Austerity measures in sub-Saharan Africa and elsewhere in the global south have made it virtually impossible for national health systems to provide quality, comprehensive primary care services to the general population. However, recent scholarship 